\title{
Modeling of the Channel Thickness Influence on Electrical Characteristics and Series Resistance in Gate-Recessed Nanoscale SOI MOSFETs
}

\author{
A. Karsenty ${ }^{1}$ and A. Chelly ${ }^{2}$ \\ ${ }^{1}$ Faculty of Engineering, Jerusalem College of Technology, 91160 Jerusalem, Israel \\ ${ }^{2}$ Faculty of Engineering, Bar-Ilan University, 52900 Ramat Gan, Israel \\ Correspondence should be addressed to A. Karsenty; karsenty@jct.ac.il
}

Received 20 December 2012; Revised 8 May 2013; Accepted 8 May 2013

Academic Editor: Gerard Ghibaudo

Copyright (C) 2013 A. Karsenty and A. Chelly. This is an open access article distributed under the Creative Commons Attribution License, which permits unrestricted use, distribution, and reproduction in any medium, provided the original work is properly cited.

\begin{abstract}
Ultrathin body (UTB) and nanoscale body (NSB) SOI-MOSFET devices, sharing a similar W/L but with a channel thickness of $46 \mathrm{~nm}$ and lower than $5 \mathrm{~nm}$, respectively, were fabricated using a selective "gate-recessed" process on the same silicon wafer. Their current-voltage characteristics measured at room temperature were found to be surprisingly different by several orders of magnitude. We analyzed this result by considering the severe mobility degradation and the influence of a huge series resistance and found that the last one seems more coherent. Then the electrical characteristics of the NSB can be analytically derived by integrating a gate voltage-dependent drain source series resistance. In this paper, the influence of the channel thickness on the series resistance is reported for the first time. This influence is integrated to the analytical model in order to describe the trends of the saturation current with the channel thickness. This modeling approach may be useful to interpret anomalous electrical behavior of other nanodevices in which series resistance and/or mobility degradation is of a great concern.
\end{abstract}

\section{Introduction}

Nanoscale silicon-on-insulator (SOI) metal-oxide-semiconductor field-effect transistor (MOSFET) based devices are the building blocks of up-to-date systems allowing ultrafast data processing. This is in accordance with efforts to develop new generation of ultra-fast computers based on combined electronic and signal processing on one hand [1] and advanced generations of nanoscale devices (NSB) for communication systems $[2,3]$ on the other hand. In this paper, we report the influence of the silicon channel thickness on the electrical characteristics of SOI MOSFET NSB, and we present an accurate model permitting to evaluate the series resistance and the saturation current as a function of the thickness or of the gate voltage, when part of the aim is to explain the anomalous transport behavior of the thinner channels having a channel's thickness as low as $1.6 \mathrm{~nm}$ and obtained by a selective gate-recessed process [4].

The excellent control of the short channel effects, achievable by means of UTB SOI MOSFET architectures, makes them good candidates for ultimate nanometrics scale. Consequently, the transport properties' study of thin semiconductor films has attracted considerable attention in the recent years.

In this paper, we present the influence of the NSB's channel thickness on the series resistance in order to complete the unified model of the NSB's electrical characteristics. In addition to last years' existing knowledge in series resistance, these novel interpretative approach and analytical model can be useful for the prediction of transport phenomena at the nanoscale and the correction of electrical characteristics.

\section{Methodology}

2.1. SIMOX Preferred Wafer Processing Technology. Several techniques were developed in the past to create silicon-oninsulator (SOI) devices [5-8], since their implementation was found promising [9-11] for ULSI [12], low power [13], military and space [14], and cost reducing [15] applications. Nowadays, SOI wafers are mainly fabricated using the UNIBOND 


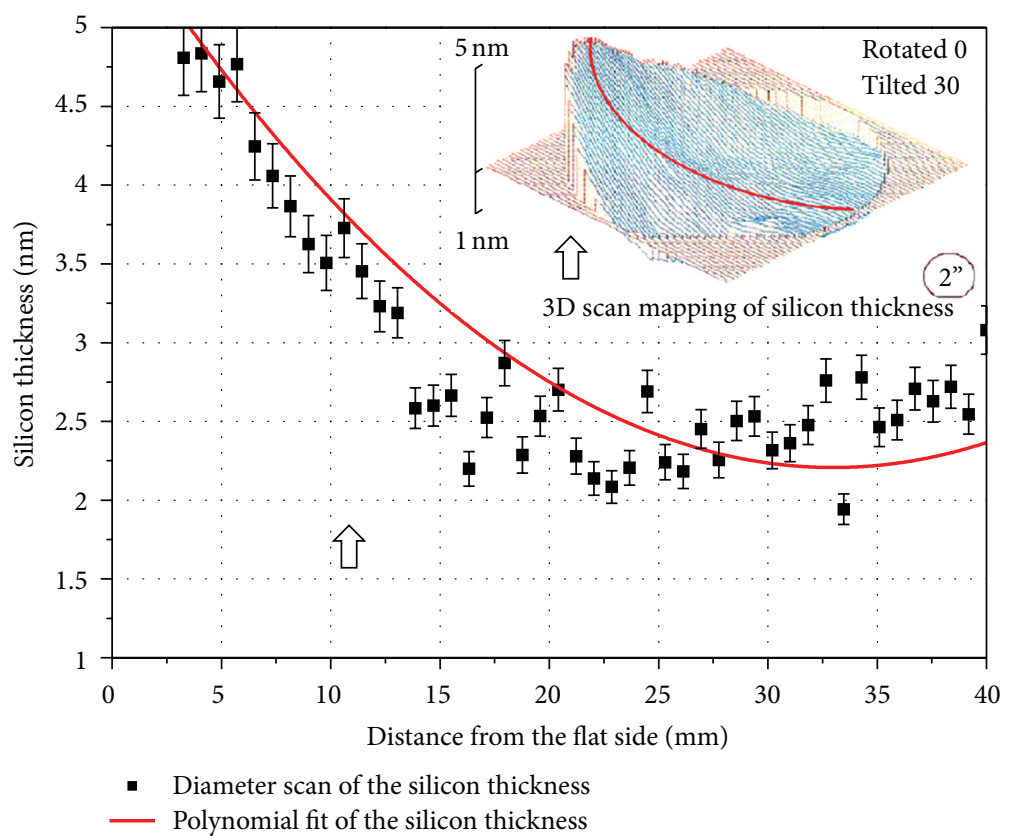

FIGURE 1: Gradient of SOI thicknesses measured by spectrophotometry across a $2^{\prime \prime}$ diameter SIMOX test wafer after thinning using the gate-recessed process. The fitting curve here is serving as a visual guide of the thickness distribution.

line of SOI wafers and the smart cut process technologies, patented by SOITEC Company, allowing excellent thickness uniformity [16]. However, for this research purpose, the former SOITEC technology called Separation-by-IMplantedOxygen (SIMOX) was preferred because of the clear advantage of presenting an initial gradient of the SOI thickness across the same wafer. This desirable gradient is conserved during the processing of the nanoscale body (NSB) devices as shown in Figure 1, in which are presented spectrophotometry measurements of SOI thicknesses gradient across a $2^{\prime \prime}$ diameter SIMOX test wafer after thinning using the gate-recessed process. Consequently, it is possible to study the thickness influence on the NSB electrical characteristics. In Figure 2, the tested NSB devices are presented with their respective channel thicknesses ranging from 1.6 to $4.6 \mathrm{~nm}$ as measured by spectrophotometry. The accuracy of the critical channel thickness of $1.6 \mathrm{~nm}$ was confirmed by in ex situ HRTEM measurement.

2.2. Accurate Calibration of the Oxidation Furnace. The most challenging step was the accurate controlled thinning process of the SOI layer using local oxidation in the sub $10 \mathrm{~nm}$ range of thickness, while the source and the drain regions remained in their original thickness. In order to check the capability of accurate thinning, preliminary tests of thinning were performed in order to reach thicknesses lower than $10 \mathrm{~nm}$, when characterizing the furnace parameters like furnace temperature, duration of the oxidation, and growth rate [17].

2.3. Device Processing Using Recessed-Gate Channel Technology. The local oxidation was performed by using a nitride mask layer of $38 \mathrm{~nm}$ (nitride 1) grown on a thin oxide layer

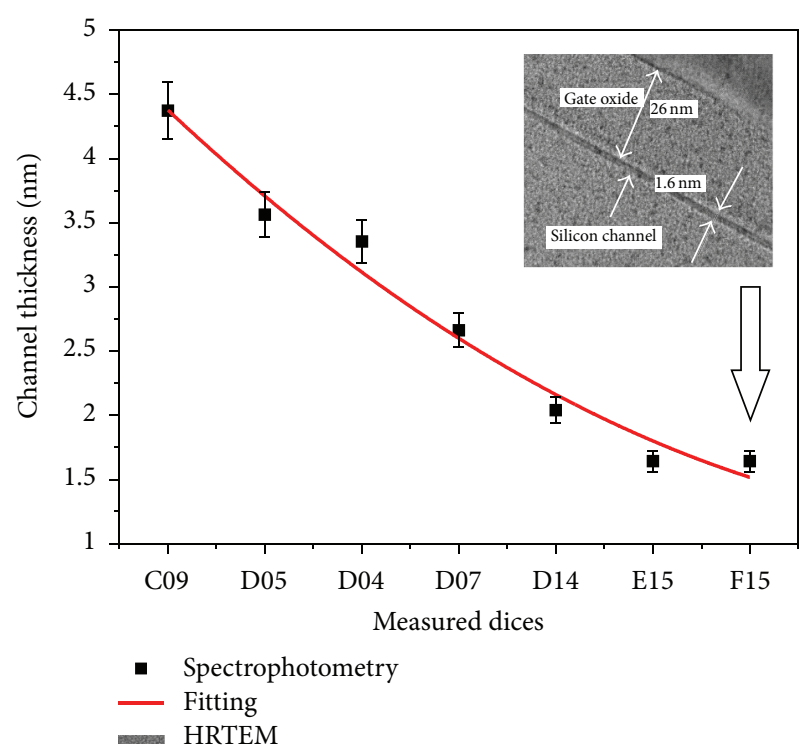

FIGURE 2: Spectrophotometry measurements of the channel thickness performed on the tested dices containing Nano-Scale Body (NSB) devices (from 4.4 to $1.6 \mathrm{~nm}$ ). The dices were cut from the same $2^{\prime \prime}$ diameter SIMOX wafer. The accuracy of the measurements is confirmed by inserted HRTEM picture for the smallest channel thickness value $(1.6 \mathrm{~nm})$. The fitting is serving as a visual guide of the thickness distribution.

(PAD OX) of $15 \mathrm{~nm}$. The role of the pad oxide was to serve as an interface between the nitride and the silicon to prevent mechanical stresses. A first etching of the nitride and pad oxide layer at the extremities of the active region allowed their oxidation into a $700 \mathrm{~nm}$ thick field oxide (FOX). A second 
etching, performed at the center of the nitride region, allowed exposure of the channel region, while the surrounding nitride capped the source and drain areas. Two steps of oxidation were then performed. First, a $75 \mathrm{~nm}$ thick sacrificial oxide layer, called channel oxide (CHAN OX), was grown in order to significantly decrease the channel's thickness to about $10 \mathrm{~nm}$, before removal. The second phase of the oxidation ( $25 \mathrm{~nm}$ thick), called gate oxidation (GOX), was a more accurate step making possible a final nanoscale thickness of the channel, in the range of $1.6 \mathrm{~nm}$ to $6.5 \mathrm{~nm}$, and serving as the gate oxide itself, when the thickness distribution uniformity and the $\mathrm{Si}_{-} \mathrm{SiO}_{2}$ interface quality [18] are serving as important parameters $[19,20]$. In order to get reference devices, that is, having an initial silicon channel close to $46 \mathrm{~nm}$, the nitride mask was not etched, so the gate insulator layer is made of the $38 \mathrm{~nm}$ thick nitride layer deposited on the $15 \mathrm{~nm}$ PAD OX layer.

2.4. Fabrication of the Contact Electrodes. Then, a polycrystalline silicon layer of $220 \mathrm{~nm}$ was deposited over the gate oxide, oxidized, and patterned to form the gate electrode. Before the source/drain/gate phosphorus implant, a thin layer nitride (nitride 2) of $30 \mathrm{~nm}$ was deposited in order to prevent further oxidation of the thin silicon layer during the implant's thermal annealing. A Plasma-enhanced chemical vapor deposition (PECVD) oxide (silox 2) of $350 \mathrm{~nm}$ thickness was deposited followed by an aluminum metallization step to define the contact areas.

2.5. TCAD Simulation of the Device Processing. In order to perform a deeper and accurate analysis of the process limitations, the layers deposition process was translated to a model of the device using TCAD (TSUPREM-4) software. One of the main outputs of the program is the $2 \mathrm{D}$ device crosssection, which includes among others the exact boundaries of the various layers of materials in the structure.

In Figure 3, we present a cross-section of the NSB including the source, gate, and drain (resp., S, G, and D) parts and a zoom of the gate-recessed silicon channel. As presented in the upper insert, the active region (source, gate, and drain terminals) which is built of layers described previously, is terminated by aluminum contacts (layer 10) in the vertical axis and limited by field oxide (layer 07) borders in the horizontal axis. The buried oxide (layer 02) is serving as a barrier between the bulk silicon (layer 01) and the gaterecessed silicon channel (layer 03).

The lower insert of Figure 3 represents a zoom-in of the gate-recessed channel, when the silicon layer was thinned from $46 \mathrm{~nm}$ to $1.6 \mathrm{~nm}$ minimal thickness, as confirmed by HRTEM picture in Figure 2. This points out the advantage of the recessed process in which only the silicon channel is thinned, while the source and the drain extensions remain in their original thickness. So the series resistance of the drain and of the source should not be affected $a$ priori by the thinning process.

In addition to Figure 3, presenting a simulated TCAD cross-view of the device layers, a complementary list of the process parameters was presented in summarizing Table 1.

\section{Results}

3.1. $I_{\mathrm{DS}}-V_{\mathrm{GS}}$ Characteristics in the Linear Domain. Using the semiconductor characterization system (SCS-4200) from Keithley Ltd., $I-V$ measurements (room temperature, dark conditions) were performed on a selection of four NSB devices (E15, G15, C12, and C03), having the same channel width and length $(W / L=80 \mu \mathrm{m} / 8 \mu \mathrm{m})$ but a channel thickness $\left(t_{\mathrm{SI}}\right)$ below $5 \mathrm{~nm}: 1.6,2.4,2.9$, and $4.9 \mathrm{~nm}$, respectively. Since the front gate oxide (GOX) thickness is $26 \mathrm{~nm}$, as checked by HRTEM and ellipsometry, the front gate capacitance $\left(C_{\mathrm{ox}}\right)$ is evaluated to $138 \mathrm{nF} / \mathrm{cm}^{2}$. Back gate contact was kept floating for all devices. The drain currents $\left(I_{\mathrm{DS}}\right)$ versus gate voltage $\left(V_{\mathrm{GS}}\right)$ characteristics (from -4 to $+4 \mathrm{~V}$ ) were measured in the linear domain (constant low $V_{\mathrm{DS}}=0.1 \mathrm{~V}$ ) and are presented in Figure 4 for the four NSBs.

By increasing $V_{\mathrm{GS}}$ from $-4 \mathrm{~V}$ to $-1 \mathrm{~V}, I_{\mathrm{DS}}$ slowly decreases and slightly depends on $t_{\mathrm{SI}}$, indicating a leakage phenomenon (negative resistance) similar to the gate-induced drain leakage (GIDL) observed for both classic and SOI-MOSFET devices [21].

For $V_{\mathrm{GS}}$ from $-1 \mathrm{~V}$ to $-0.5 \mathrm{~V}$, the steep linear increasing observed at least for $t_{\mathrm{SI}}=4.9 \mathrm{~nm}$, which is combined to the low order of magnitude, characteristic of the subthreshold regime. We note that the subthreshold slope is strongly degraded by decreasing the channel thickness.

However, for positive $V_{\mathrm{GS}}$ values, above the apparent threshold voltage located around $-0.5 \mathrm{~V}$, the characteristics are bent and turned into a linear dependence on $V_{\mathrm{GS}}$ indicating a constant transconductance $g_{m}$ in the whole positive domain of $V_{\mathrm{GS}}$. Since our devices are considered as long channel devices $(L=8 \mu \mathrm{m})$, the effective mobility $\left(\mu_{\text {eff }}\right)$ can be extracted from $g_{m}$ in the linear domain by the following equation based on the classic gradual channel approximation:

$$
\begin{aligned}
& \text { for } V_{\mathrm{GS}} \geq 0 \\
& \left.g_{m} \equiv \frac{\partial I_{\mathrm{DS}, \text { lin }}}{\partial V_{\mathrm{GS}}}\right|_{V_{\mathrm{DS}}}=\frac{W}{L} \mu_{\mathrm{eff}}\left(\frac{\partial Q_{n}}{\partial V_{\mathrm{GS}}}\right) V_{\mathrm{DS}} \sim \frac{W}{L} \mu_{\mathrm{eff}} C_{\mathrm{ox}} V_{\mathrm{DS}} \\
& \text { so } \mu_{\mathrm{eff}}=\frac{L g_{m, \mathrm{lin}}}{W C_{\mathrm{ox}} V_{\mathrm{DS}}} .
\end{aligned}
$$

According the extracted values $g_{m}$ from Figure 4 for $V_{\mathrm{DS}}=0.1 \mathrm{~V}$ and for other $V_{\mathrm{DS}}$ values (lower than $0.5 \mathrm{~V}$ to stay in the linear domain), we can estimate the effective mobility $\left(\mu_{\mathrm{eff}}\right)$ independently of $V_{\mathrm{GS}}$ and $V_{\mathrm{DS}}$ for the four NSBs as seen in Figure 5.

Surprisingly the values were found lower than $10 \mathrm{~cm}^{2} / V_{s}$ and weakly decreasing with $t_{\mathrm{SI}}$. However, as far as we know, such a low order of magnitude was never reported in the main works dealing with sub $5 \mathrm{~nm}$ nanoscale SOI-MOSFET devices [22-24]. Moreover, the effective mobility is expected to decrease at low and high effective field values (due to the interface scattering degradation factor [25]), so $g_{m}$ should decrease with $V_{\mathrm{GS}}$ and not be a constant with $V_{\mathrm{GS}}$ as seen from Figure 4 . 


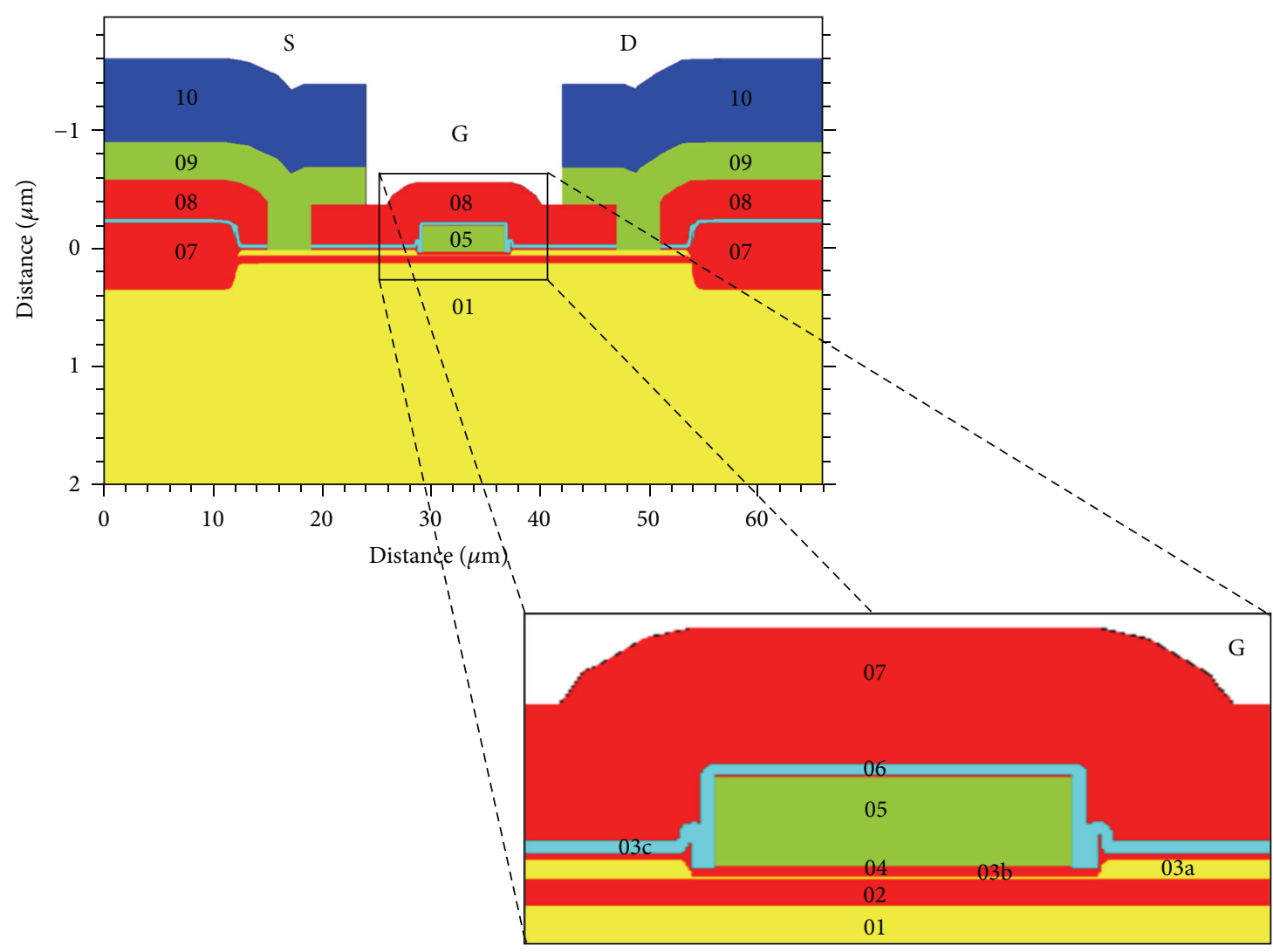

01: bulk silicon
02: buried oxide (BOX)
03a: original silicon-on-insulator
03b: gate-recessed silicon channel
03c: pad oxide (PAD OX)
04: gate oxide (GOX)
05: polysilicon
06: nitride

07: field oxide (FOX)

08: silox

08: silox (SOX)

09: polysilicon source/drain contact

10: aluminum

S: source

G: gate

D: drain

Figure 3: Cross-view of a TCAD (Tsuprem4) simulated nanoscale devices using the gate-recessed channel process. The layers deposition sequence is described in the text.

3.2. Effective Mobility versus Series Resistance at Zero $V_{\mathrm{GS}}$. The electron mobility in similar SOI-MOSFETs is known to be strongly degraded by decreasing the channel thickness below $5 \mathrm{~nm}$. Several important works have attributed the degradation to a combination of Coulomb scattering generated by surface states [23], surface roughness [24-26], and enhanced phonon [27] scattering mechanisms. According to [23], the surface roughness is described as a quantum effect mechanisms dominating at low temperature but strongly dependent on the channel thickness $t_{\mathrm{SI}}$ below $4 \mathrm{~nm}$ even at room temperature. The mobility is found to decrease theoretically as a $t_{\mathrm{SI}}^{6}$ law.

Such a discrepancy with our extracted effective mobility behavior inclined us to interpret our measurements in terms of a parasitic drain-source series resistance that overwhelm the intrinsic channel conductance $g_{d}$ and "screen" the previously cited scattering mechanisms.

Indeed, it is well established that if source drain series resistance $R_{\mathrm{SD} 0}$ competes with the channel conductance a decreasing of the drain current can be measured [28]. In the linear domain, at zero $V_{\mathrm{GS}}$, the drain current can be described by the following equation:

$$
\begin{aligned}
& \text { For } V_{\mathrm{GS}}=0 \geq V_{T}, \\
& I_{\mathrm{DS}, \text { lin }}=\left(\frac{g_{d}}{1+g_{d} R_{\mathrm{SD} 0}}\right) V_{\mathrm{DS}} \longrightarrow \frac{V_{\mathrm{DS}}}{R_{\mathrm{SD} 0}} \text { for } g_{d} \ll R_{\mathrm{SD} 0},
\end{aligned}
$$

where $g_{d}$ is the conductance of the channel. 
TABLE 1: Process parameters for deposited layers.

\begin{tabular}{|c|c|c|c|c|}
\hline $\begin{array}{l}\text { Layer } \\
\text { number }\end{array}$ & Layer name & Layer acronym & $\begin{array}{c}\text { Layer } \\
\text { thickness [nm] }\end{array}$ & Function and properties \\
\hline 01 & Bulk silicon & Bulk & & $\begin{array}{l}\text { Substrate p-type }\left(10^{15} \mathrm{~cm}^{-3}\right) \\
\text { Resistivity: } 14-22 \Omega \cdot \mathrm{cm} \\
\text { Orientation }\langle 100\rangle\end{array}$ \\
\hline 02 & Buried oxide & BOX & 70 & $\begin{array}{l}\text { Bulk insulator } \\
\left.\mathrm{O}^{+} \text {implantation energy: } 120 \mathrm{keV} \text { ( } 2.35 \text { hours }\right) \\
\text { Dose: } 0.3910^{18} \mathrm{O}^{+} / \mathrm{cm}^{2} \\
\text { Anneal: } 1320^{\circ} \mathrm{C}(6.00 \text { hours })\end{array}$ \\
\hline $03 a$ & Silicon-on-insulator & SOI & 46 & $\begin{array}{l}\text { p-type }\left(10^{15} \mathrm{~cm}^{-3}\right) \text { regular transistor channel in UTB devices and } \\
\text { nonreduced SOI in NSB devices (source-drain extensions) }\end{array}$ \\
\hline $03 \mathrm{~b}$ & Gate-recessed silicon & GRS & $1.6-6.5$ range & Thinned transistor channel in NSB devices \\
\hline $03 \mathrm{c}$ & Pad oxide & PAD OX & 15 & Relieve stress from silicon to nitride at high temperature \\
\hline 04 & Gate oxide & GOX & 26 & Gate insulator \\
\hline 05 & Polysilicon & Poly & 220 & Gate electrode \\
\hline 06 & Nitride 2 & Nit & 30 & $\begin{array}{l}\text { Prevent further oxidation of the thin silicon layer during the } \\
\text { implant's thermal annealing (NSB) }\end{array}$ \\
\hline 07 & Field oxide & FOX & 700 & Active area insulator \\
\hline 08 & Silox & SOX & 350 & Contact opening mask for source/drain and gate passivation \\
\hline 09 & Polysilicon & Poly & 220 & $\begin{array}{l}\text { Source/drain polycontacts } \\
\text { Source/drain doping obtained by phosphorous implant } \\
\text { Dose } D=2.510^{15} \mathrm{~cm}^{-2} \text { Energy } E=30 \mathrm{keV} \\
\text { HTA High temperature annealing } T=1000^{\circ} \mathrm{C},(30 \mathrm{~min})\end{array}$ \\
\hline 10 & Aluminum & $\mathrm{Al}$ & 500 & Source/drain metal contacts \\
\hline
\end{tabular}

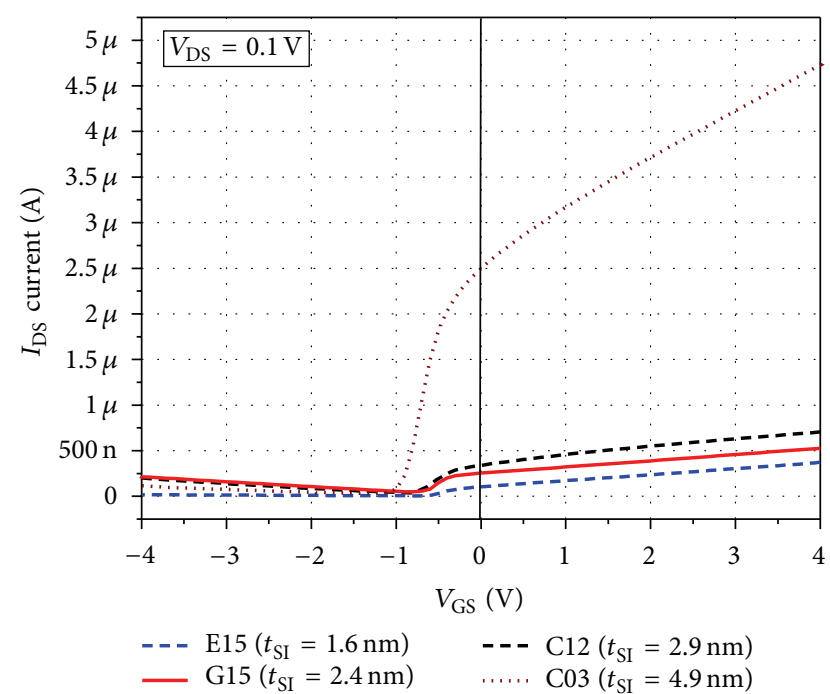

FIGURE 4: $I_{\mathrm{DS}}-V_{\mathrm{GS}}$ characteristics measured at $V_{\mathrm{DS}}=0.1 \mathrm{~V}$ for four NSB devices (dices E15, G15, C12, and C03) having a channel thickness $\left(t_{\mathrm{SI}}\right)$ of $1.6,2.4,2.9$, and $4.9 \mathrm{~nm}$, respectively.

Thus, by dividing the $V_{\mathrm{DS}}$ fixed value $(0.1 \mathrm{~V})$ by the intercept value of $I_{\mathrm{DS}}$ at zero $V_{\mathrm{GS}}$ a very large series resistance $\left(R_{\mathrm{SD} 0}\right)$ can be calculated. By varying $V_{\mathrm{DS}}$ for low values (below $0.4 \mathrm{~V}$ ), we got a linear dependence of $I_{\mathrm{DS}}$ with $V_{\mathrm{DS}}$ at zero $V_{\mathrm{GS}}$, that is, confirmed explicitly by (3).
In Figure 6, the $R_{\mathrm{SD} 0}$ values, as extracted from Figure 4, and $\mu_{\mathrm{eff}}$, evaluated from (1), are plotted versus the four selected channel thicknesses. The classic $R_{\mathrm{SD} 0}$ vs. $1 / t_{\mathrm{SI}}$ hyperbolic decay due to the current spreading is plotted for reference but could not match the extracted values. As seen in the same figure, the best fit is found exponential as follows:

$$
R_{\mathrm{SD} 0}=R_{\mathrm{SD} 0}^{*} e^{-t_{\mathrm{SI}} / t_{0}}
$$

with $R_{\mathrm{SD} 0}^{*}=4.54 \mathrm{M} \Omega$ and $t_{0}=1.03 \mathrm{~nm}$.

In Figure 6 , the $\mu_{\text {eff }}$ dependence on $t_{\mathrm{SI}}$ is found to be far from the theoretical $t_{\mathrm{SI}}^{6}$ dependence due to the roughness scattering $[23,24]$. Moreover, the remote Coulomb scattering due to interface charges and reported to decay exponentially with $t_{\mathrm{SI}}$ in the subdeca-nanometer range [25] cannot match the extracted values of $\mu_{\text {eff }}$. The interpretation of $R_{\mathrm{SD}}$ dependence with $t_{\mathrm{SI}}$ will be examined later in the paper (Section 4).

3.3. Extraction of the Series Resistance Degradation Factor with $V_{\mathrm{GS}}$. In Figure 4 , for positive $V_{\mathrm{GS}}$ values, the linear trend of $I_{\mathrm{DS}}$ with $V_{\mathrm{GS}}$ can be described by the following expression:

$$
\text { For } V_{\mathrm{GS}}>0, \quad I_{\mathrm{DS}, \text { lin }}=\frac{V_{\mathrm{DS}}}{R_{\mathrm{SD} 0}}+g_{m} V_{\mathrm{GS}} \text {. }
$$




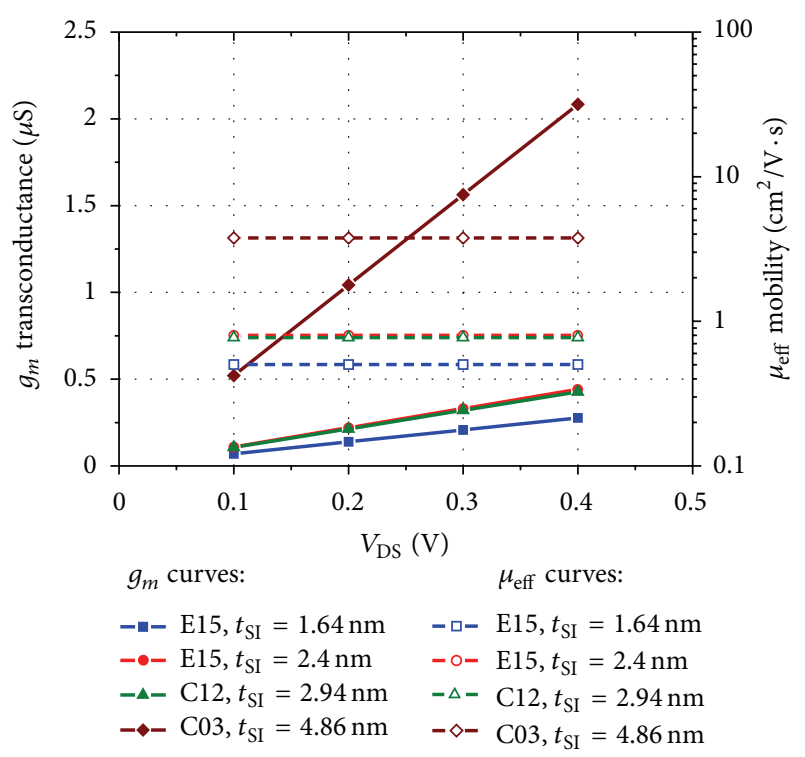

FIGURE 5: Extracted transconductance $g_{m}$ and effective mobility $\mu_{\text {eff }}$ versus $V_{\mathrm{DS}}$ for four NSB devices (dices E15, C12, G15, and C03) having a channel thickness $\left(t_{\mathrm{SI}}\right)$ of $1.6,2.4,2.9$, and $4.9 \mathrm{~nm}$, respectively. $g_{m}$ is extracted from Figure 4 as the slope of the $I_{\mathrm{DS}^{-}}$ $V_{\mathrm{GS}}$ for positive $V_{\mathrm{GS}}$.

We can generalize (3) using a $V_{\mathrm{GS}}$ dependent series resistance $R_{\mathrm{SD}}$. Since in the linear domain, $I_{\mathrm{DS} \text {, lin }}$ has a Ohmic behavior with $V_{\mathrm{DS}}$, and the $R_{\mathrm{SD}}$ expression can be extracted (5) as

For $V_{\mathrm{GS}}>0$,

$I_{\mathrm{DS}, \text { lin }} \equiv \frac{V_{\mathrm{DS}}}{R_{\mathrm{SD}}} \Longrightarrow R_{\mathrm{SD}}=\frac{R_{\mathrm{SD} 0}}{1+\left(g_{m} R_{\mathrm{SD} 0} / V_{\mathrm{DS}}\right) V_{\mathrm{GS}}} \equiv \frac{R_{\mathrm{SD} 0}}{1+\theta V_{\mathrm{GS}}}$,

where $\theta$ is the series resistance degradation factor (units $\mathrm{V}^{-1}$ ).

The decreasing of $R_{\mathrm{SD}}$ at high positive $V_{\mathrm{GS}}$ has been already observed in classic MOSFET and LDD device [29, 30]. Consequently, $\theta$ can be extracted from $g_{m}$ for a given $R_{\mathrm{SD} 0}$ and $V_{\mathrm{DS}}$ from Figure 4 . In Figure 7, $\theta$ is plotted versus the four selected channel thicknesses.

An hyperbolic fit best fit the $\theta$ decay with the channel thickness as follows:

$$
\theta=\frac{\theta^{*}}{t_{\mathrm{SI}}}
$$

with $\theta^{*}=1.1 \mathrm{~nm} \cdot \mathrm{V}^{-1}$.

Finally, the drain-source series resistance can be expressed by the following expression depending on $t_{\mathrm{SI}}$ and $V_{\mathrm{GS}}$ :

$$
R_{\mathrm{SD}}=\frac{R_{\mathrm{SD} 0}^{*} e^{-t_{\mathrm{SI}} / t_{0}}}{1+\theta^{*} V_{\mathrm{GS}} / t_{\mathrm{SI}}}
$$

3.4. $I_{\mathrm{DS}}-V_{\mathrm{DS}}$ Characteristics and Model of the Saturation Current for NSB. In Figure 8 we present the measured $I_{\mathrm{DS}}-V_{\mathrm{DS}}$ characteristics (sweeping $V_{\mathrm{DS}}$ from 0 to $15 \mathrm{~V}$ ) for $V_{\mathrm{GS}}=4 \mathrm{~V}$

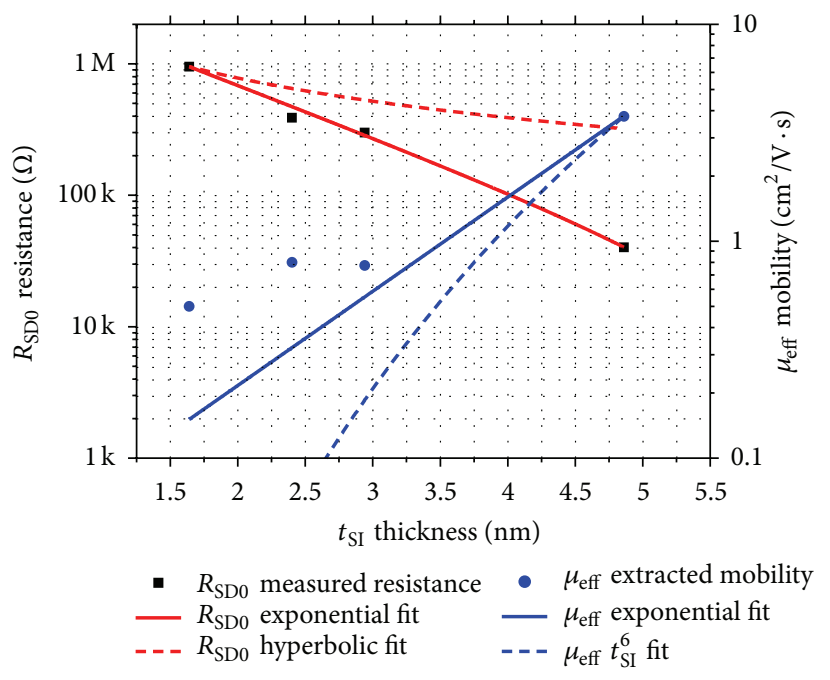

FIGURE 6: Semilog plot of $R_{\mathrm{SD} 0}$ and $\mu_{\text {eff }}$ versus channel thickness for four NSB devices (dices E15, C12, G15, and C03) having a channel thickness $\left(t_{\mathrm{SI}}\right)$ of $1.6,2.4,2.9$, and $4.9 \mathrm{~nm}$, respectively. $R_{\mathrm{SD} 0}$ is extracted from Figure 4 as the ratio of the $V_{\mathrm{DS}}$ constant value $(0.1 \mathrm{~V})$ to the drain current measured at zero $V_{\mathrm{GS}} \cdot \mu_{\mathrm{eff}}$ is extracted from (2).

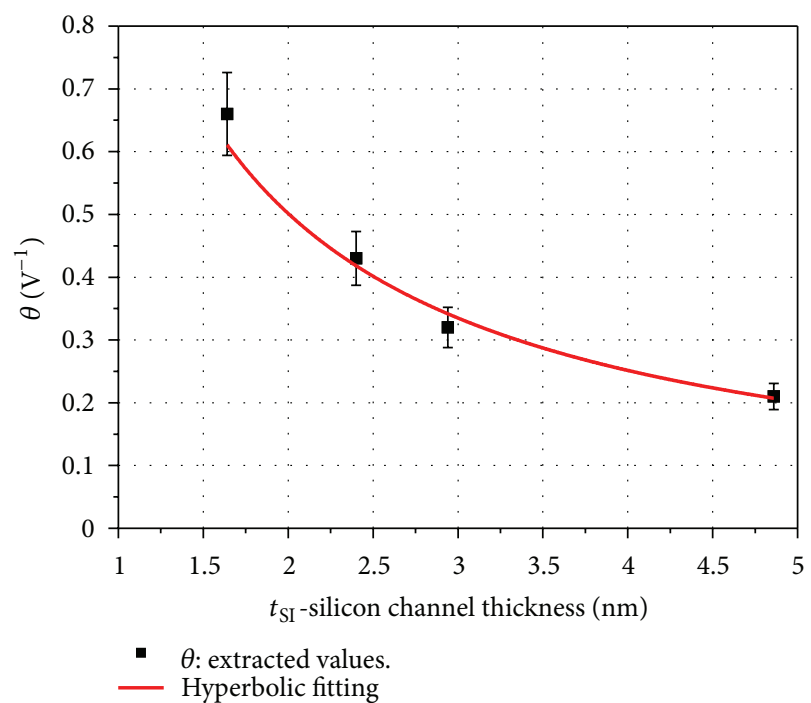

FIGURE 7: plot of theta versus the four channel thicknesses.

for NSB having, respectively, a channel thickness of 4.9 and $1.6 \mathrm{~nm}$. On the one hand, for a given $V_{\mathrm{GS}}$, the saturation current is decreased by decreasing the channel thickness $t_{\mathrm{SI}}$. On the other hand, for a given $V_{\mathrm{GS}}$, the saturation voltage is almost constant by decreasing the channel thickness. We propose a model to describe these saturation trends with $t_{\mathrm{SI}}$.

3.5. Dependence of the Saturation Current $I_{\mathrm{DS}}$, sat on the Channel Thickness $t_{\mathrm{SI}}$ for NSB. Assuming that, for a given $V_{\mathrm{GS}}$, the variation of the NSB's saturation voltage $V_{\mathrm{DS} \text {,sat }}$ is 


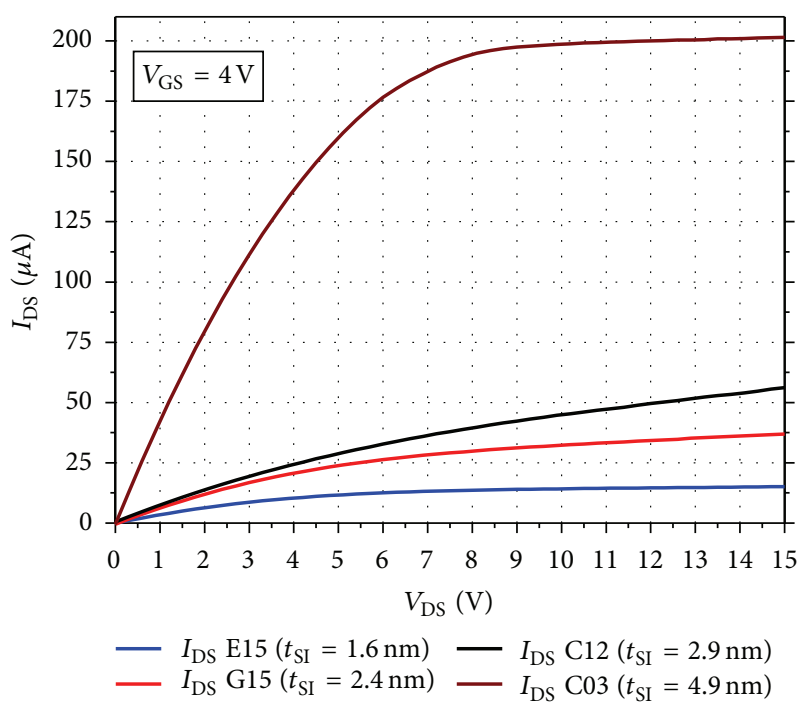

FIGURE 8: Measured $I_{\mathrm{DS}}-V_{\mathrm{DS}}$ characteristics for NSB's thickness for four NSB devices (dices E15, C12, G15, and C03) having a channel thickness $\left(t_{\mathrm{SI}}\right)$ of $1.6,2.4,2.9$, and $4.9 \mathrm{~nm}$, respectively.

mainly due to the $R_{\mathrm{SD}}$ drop voltage, and we can write the following:

$$
\Delta V_{\mathrm{DS}, \mathrm{sat}} \approx \Delta\left(R_{\mathrm{SD}} I_{\mathrm{DS}, \mathrm{sat}}\right) .
$$

Since the variation of $V_{\mathrm{DS} \text {,sat }}$ is found weak with the $t_{\mathrm{SI}}$ especially below $4 \mathrm{~nm}$, we can derive from (9)

$$
\begin{aligned}
\Delta V_{\mathrm{DS}, \text { sat }} \approx 0 & \Longrightarrow R_{\mathrm{SD}} \Delta I_{\mathrm{DS}, \text { sat }} \approx-I_{\mathrm{DS}, \text { sat }} \Delta R_{\mathrm{SD}} \\
& \Longrightarrow \frac{\Delta I_{\mathrm{DS}, \mathrm{sat}}}{I_{\mathrm{DS} \text {,sat }}} \approx-\frac{\Delta R_{\mathrm{SD}}}{R_{\mathrm{SD}}} .
\end{aligned}
$$

From (8) we can approximate (10) for $V_{\mathrm{GS}}=4 \mathrm{~V}$ and low $t_{\mathrm{SI}}$ by

$$
\frac{\Delta R_{\mathrm{SD}}}{R_{\mathrm{SD}}} \approx-\frac{t_{\mathrm{SI}}}{t_{0}} .
$$

By integrating (10) for $V_{\mathrm{GS}}=4 \mathrm{~V}$ we get finally the modeled saturation current as function of the channel thickness $t_{\mathrm{SI}}$ according to

$$
I_{\mathrm{DS}, \mathrm{sat}}\left(V_{\mathrm{GS}}=4 \mathrm{~V}\right) \sim I_{0}\left(V_{\mathrm{GS}}=4 \mathrm{~V}\right) \cdot e^{t_{\mathrm{SI}} / t_{0}} .
$$

In Figure 9, the modeled saturation current from (12) is plotted versus the channel thickness for NSBs. We can notice a good agreement with the measured saturation current (for $V_{\mathrm{DS}}=15 \mathrm{~V}$ and $V_{\mathrm{GS}}=4 \mathrm{~V}$ ) for the different NSB's channel thicknesses.

\section{Complementary Results for the Elucidation of Series Resistance}

In order to corroborate our interpretation and to discriminate it from the carrier mobility, we added several

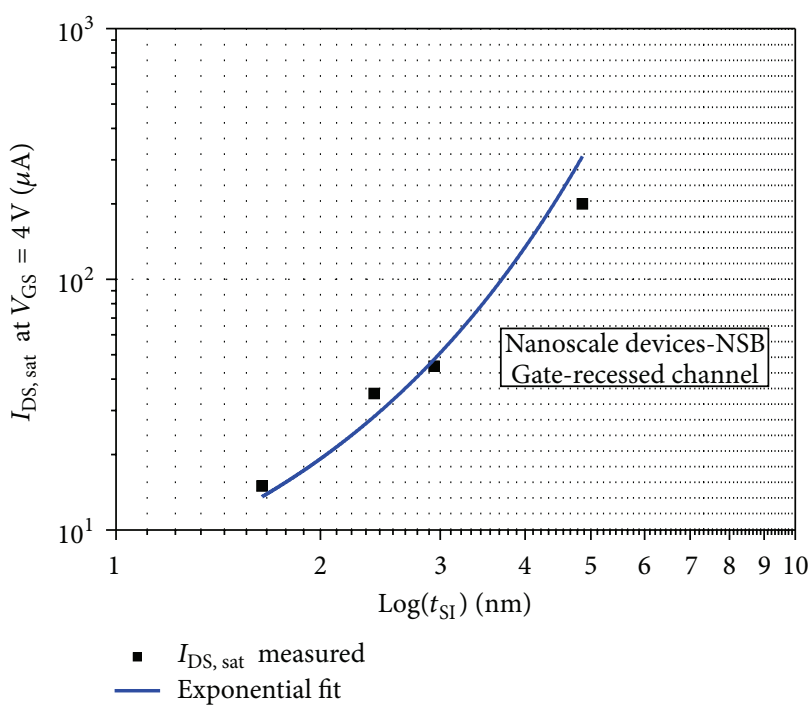

FIGURE 9: Measured saturation current (for $V_{\mathrm{GS}}=4 \mathrm{~V}$ and $V_{\mathrm{DS}}=$ $15 \mathrm{~V}$ ) versus channel thickness for NSB devices and fitted by the model given by (12).

results based on the classic $R_{m}-L$ technique [31, 32] and the gate-to-channel capacitance measurement (or "split $C-V$ " method) [33]. $R_{m}$ is the measured resistance of the device defined by the reciprocal slope of the $I_{\mathrm{DS}}-V_{\mathrm{DS}}$ linear characteristics, that is, $1 / g_{d}$. We compared the measurements between two kinds of devices: NSB devices having a channel thickness of $1.6 \mathrm{~nm}$ and reference UTB devices, having a $46 \mathrm{~nm}$ channel thick. The channel width is fixed to $80 \mu \mathrm{m}$.

4.1. $R_{m}-L$ Technique. In Figure 10, we compared for both the devices, the measured $R_{m}$ taken at different gate lengths ( $L=6 \mu \mathrm{m}, 8 \mu \mathrm{m}$, and $100 \mu \mathrm{m}$ ), and for different positive gate voltages $\left(V_{\mathrm{GS}}=0 \mathrm{~V}, 1 \mathrm{~V}\right.$, and $\left.4 \mathrm{~V}\right)$. For the UTBs, $R_{m}$ exhibits a linear growth trend with $L$, and a decreasing trend with $V_{\mathrm{GS}}$ as expected from the classic MOSFET channel resistance $[31,32]$. Surprisingly, for NSB devices, $R_{m}$ is found almost constant with $L$. This result indicates that the contribution of the channel resistance $R_{\mathrm{ch}}$ may be negligible for our devices. Assuming that $R_{m}$ is a serial association of $R_{\mathrm{ch}}$ with the series source-drain resistance $R_{\mathrm{SD}}, R_{m}$ can be then approximated by $R_{\mathrm{SD}}$.

Moreover, as seen in Figure 10, for NSB devices, $R_{m}$ is found decreasing with $V_{\mathrm{GS}}$. This is consistent with the trend already described in (6) for $L=8 \mu \mathrm{m}$. Therefore, these results indicate that the NSB resistance is not related to the intrinsic channel resistance but is apparently overwhelmed by an external series resistance that is almost independent of $L$. Although, series resistance is usually an association of contributions such as sheet contact resistance, spreading resistance, and other "wire resistance" [34, pages 223-225], none of these contributions exhibits the strong channel dependence like what is observed here. In our case, the measures resistance should be related to another scattering phenomenon. 


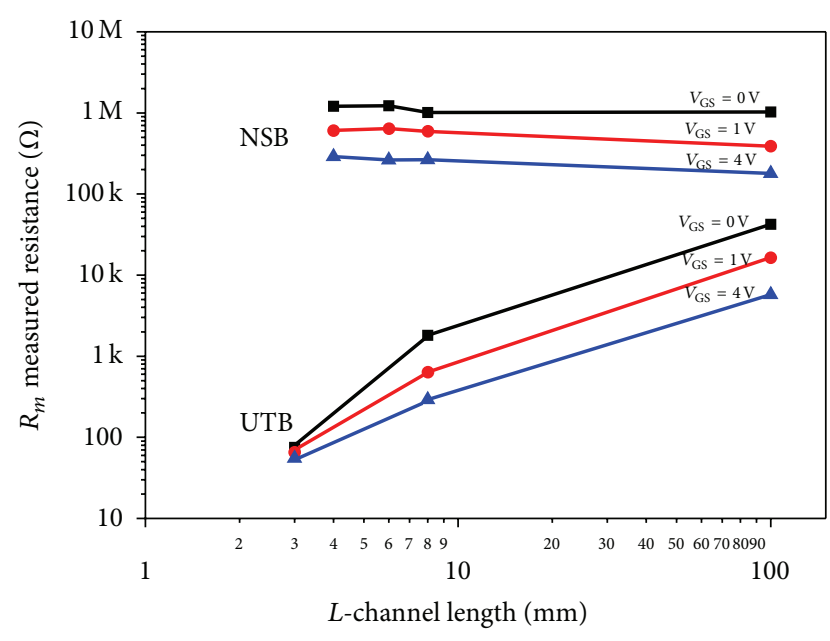

FIGURE 10: Comparison of the measured resistance $R_{m}$ for NSB's devices having a channel thickness of $1.86 \mathrm{~nm}$, with UTBs devices (46 nm channel thick), as function of channel length $(L)$ and several $V_{\mathrm{GS}}$ positive values.

4.2. Gate-to-Channel Capacitance $C_{\mathrm{GC}}$ versus Gate Voltage $V_{\mathrm{Gs}}$. In order to investigate the contribution of the inversion layer of the channel to the electrical conduction of the NSB, the gate-to-channel capacitance $\left(C_{\mathrm{GC}}\right)$ were measured versus $V_{\mathrm{GS}}$ for two frequencies ( $f=100 \mathrm{kHz}$ and $f=1 \mathrm{MHz}$ ) and compared to UTB's results. In this setup, the drain and source contacts are connected together to the voltage supply, while the substrate contact is grounded to shunt the sourcesubstrate and drain-substrate capacitances. As presented in Figure 11, it clearly appears that below the threshold voltage $V_{T}$ (about $-0.5 \mathrm{~V}$ ) the UTB's gate-to-channel capacitance is limited by a large overlap (or fringing) capacitance $2 C_{\text {ov }}$ of about $4.5 \mathrm{pF}$ and $3.9 \mathrm{pF}$ at $1 \mathrm{MHz}$ and $100 \mathrm{kHz}$, respectively. The overlap or fringing regions are located at the channel edges and/or the source and drain extension regions beside the channel. The positive shift of the capacitance with the frequency may be due to the influence of the cable capacitance on the offset capacitance value (significant at $1 \mathrm{MHz}$ ). Above $V_{T}, C_{\mathrm{GC}}$ increases and saturates, since the contribution of the channel capacitance $\left(C_{\mathrm{CH}}\right)$ is increasing and gets into its strong inversion value as observed in SOI-MOSFET [35]. However, the hump amplitude $(0.4 \mathrm{pF})$ is found lower than the value expected for the UTB's front gate capacitance $(0.8 \mathrm{pF})$. The similitude of the UTB curves for the both frequencies shows that the interface traps below the gate are not responding and then are negligible for these devices.

For the NSB device having the same dimensions than the previous UTB $(W / L=80 / 8(\mu \mathrm{m}))$ but a channel thickness as low as $1.4 \mathrm{~nm}$ and below $V_{T}, C_{\mathrm{GC}}$ is also limited by a large overlap (or fringing) capacitance $2 C_{\text {ov }}$ (both extensions regions) of about $6 \mathrm{pF}$ and $7.3 \mathrm{pF}$ at $1 \mathrm{MHz}$ and $100 \mathrm{kHz}$, respectively. The small difference of $C_{\text {ov }}$ between NSB and UTB may be due to the additional parasitic capacitance due to the thinning process. Like UTB's $C_{\mathrm{GC}}$ increases and saturates with hump amplitude of $0.7 \mathrm{pF}$ still lower than the expected value for the NSB's front gate capacitance $(0.9 \mathrm{pF})$. However, $C_{\mathrm{GC}}$ steeply decreases for positive $V_{\mathrm{GS}}$

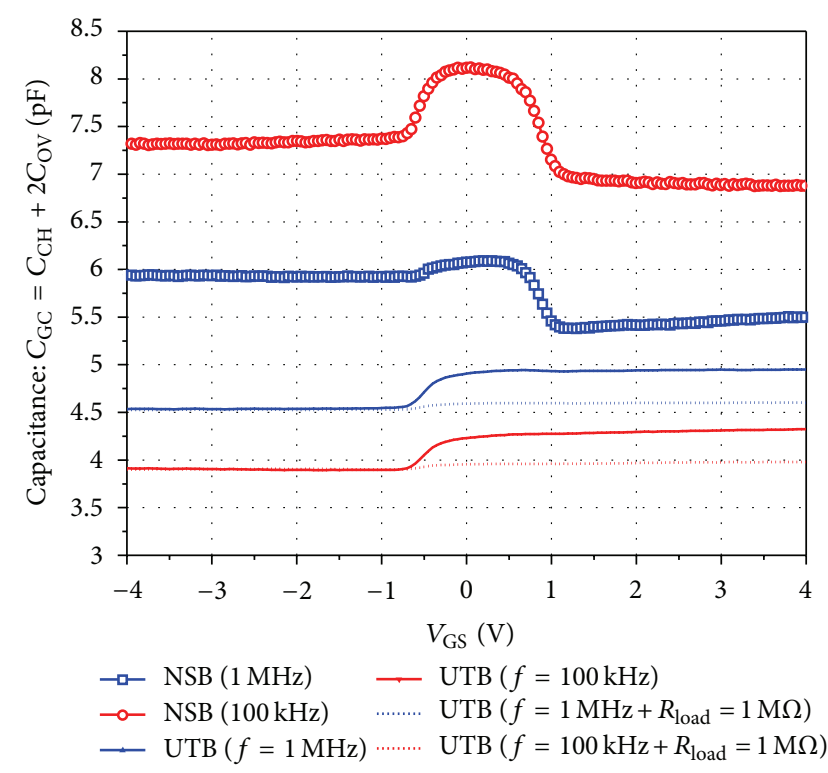

FIGURE 11: Representation of the gate-to-channel capacitance $C_{\mathrm{GC}}$ as a function of the $V_{\mathrm{GS}}$ voltage for UTB and NSB devices (at $100 \mathrm{kHz}$ and $1 \mathrm{MHz}$ ).

before saturating to a value lower than the initial $2 C_{\mathrm{ov}}$ value. Moreover, the $C_{\mathrm{GC}}$ maximum at zero $V_{\mathrm{GS}}$ (contribution of the channel) decreases strongly by increasing the frequency from $100 \mathrm{kHz}$ to $1 \mathrm{MHz}$. This frequency dependence could be explained by the presence of charged interface states that contribute to an additive capacitive component to $C_{\mathrm{GC}}$ at lower frequency $[34,35]$. This is corroborated also by the degradation of subthreshold slope, as seen in Figure 4 and by the negative voltage threshold that makes our devices to be "depletion type" devices. These interface traps, located below the gate and at the upper silicon/silicon oxide interface, may be introduced during the thinning (oxidation) step of the gate-recessed process. Consequently, these trapped charges may also contribute to the Coulomb scattering as mentioned above [23] and contribute to the exponential decay of the measured resistance.

In order to check the influence of a huge series resistance on the previous $C_{\mathrm{GC}}-V_{\mathrm{GS}}$ graph a serial load resistance of $1 \mathrm{M} \Omega$ is connected between the voltage supply and the UTB's source. From Figure 11, we can see that the capacitance hump is drastically reduced (to $0.05 \mathrm{pF}$ ) for both frequencies as expected from the capacitance relationship with series resistance assuming a parallel equivalent circuit [34, pages 88-90]. The overlap capacitance is reduced to $1.5 \mathrm{pF}$ (compensated in the graph for comparison sake with unload UTB). So the series resistance may explain the decreasing of $C_{\mathrm{GC}}$ in the $0-1 \mathrm{~V}$ range for NSB devices in particular at $1 \mathrm{MHz}$ but less at $100 \mathrm{kHz}$. One can interpret this difference by the fact that the surfaces states are more responsive at lower frequency and consequently could "shield" the series resistance effect. Moreover, since $R_{\mathrm{SD}}$ is decreasing with $V_{\mathrm{GS}}$, its influence weakens at higher $V_{\mathrm{GS}}$ values, so it may explain the increase of $C_{\mathrm{GC}}$ at $V_{\mathrm{GS}}$ higher than $1 \mathrm{~V}$ at $1 \mathrm{MHz}$ for NSB devices. 


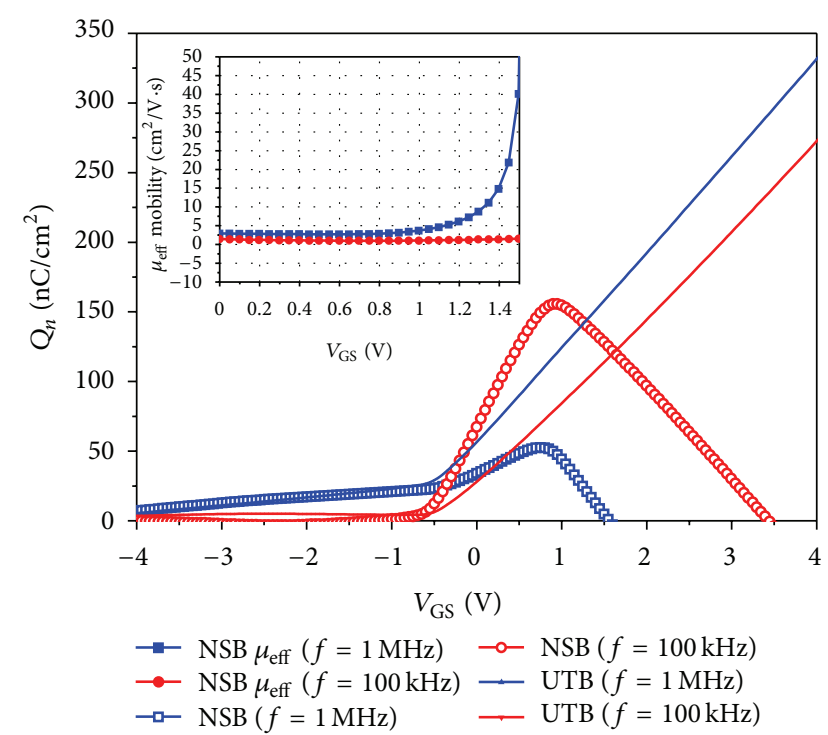

FIGURE 12: Representation of the mobile charge density $Q_{n}$ as a function of the $V_{\mathrm{GS}}$ voltage for UTB and NSB devices (at $100 \mathrm{kHz}$ and $1 \mathrm{MHz}$ ).

4.3. Mobile Charge Density and Effective Mobility Dependence with $V_{\mathrm{GS}}$. The mobile charge density $Q_{n}\left(\mathrm{C} / \mathrm{cm}^{2}\right)$ of the channel can be evaluated by integrating the previous curves $C_{\mathrm{GC}}-V_{\mathrm{GS}}$ after subtracting the $2 C_{\mathrm{OV}}$ values (to extract the channel contribution $C_{\mathrm{CH}}$ ) and by normalizing to the gate area $(80 \mu \mathrm{m} \times 8 \mu \mathrm{m})$. In Figure $12, Q_{n}$ is plotted versus $V_{\mathrm{GS}}$ for UTB and NSB at $100 \mathrm{kHz}$ and $1 \mathrm{MHz}$. While for $\mathrm{UTB}$, the mobile charge density is increasing linearly in strong inversion (above $V_{T}$ ), and it is decreasing steeply and vanishing for NSB. By combining $Q_{n}$ with the measured conductance $\left(1 / R_{m}\right)$ for a given $V_{\mathrm{GS}}$, we can extract the effective mobility according to [34, page 541]

$$
\mu_{\mathrm{eff}}=\frac{L}{W} \cdot \frac{1}{R_{m}} \cdot \frac{1}{Q_{n}} .
$$

For UTB, the mobility values extracted from (13) are compatible with the universal mobility curve [34, page 546] with an order of magnitude of $1000 \mathrm{~cm}^{2} / V s$. However, for NSB, the effective mobility values are smaller than $5 \mathrm{~cm}^{2} / \mathrm{Vs}$ (but almost constant) with VGS in the $0-1.5 \mathrm{~V}$ range at $100 \mathrm{kHz}$ (see insert in Figure 11). For $1 \mathrm{MHz}$, effective mobility is increasing with $V_{\mathrm{GS}}$. These mobility values are compatible to these extracted. As already mentioned above, this value is a too low value compared to literature for the same kind of devices. Moreover, the increase of $\mu_{\text {eff }}$ at high $V_{\mathrm{GS}}$ values observed for both frequencies is not compatible with the expected degradation of the mobility at high effective field as reported in the literature [21-27]. This reveals the limitation of the mobility extraction method based on the $C-V$ analysis in case of strong series resistance dependent on gate voltage. Consequently, in our case, the interpretation of the anomalously low conductance of the NSB relative to UTB could be better described by a series resistance model rather than by a conducting inverted channel for positive
$V_{\mathrm{GS}}$ values. Another explanation of the exponential decay of the $R_{\mathrm{SD} 0}$ with $t_{\mathrm{SI}}$ may be related to a quantum "skin-effect" phenomenon due to the electron wave function penetration at the oxide-channel interfaces [36], but here the trapping charge and coulomb scattering seem to better match our results.

\section{Conclusion}

Nanoscale SOI MOSFET devices were fabricated using a selective recess gate thinning process to get channel thicknesses scaling from $4.9 \mathrm{~nm}$ down to $1.6 \mathrm{~nm}$. The electrical characteristics were measured and interpreted as a gate controlled series resistance. The resistance is found to decay exponentially with the channel thickness. An analytical model of the saturation current for the nanoscale devices was extracted accordingly. The model is found satisfying to fit the exponential dependence of the measured saturation current with the channel thickness. As suggested by the $C-V$ dependence on frequency, this degradation may be related to a high charge density trapped at the channel-gate oxide interface. We admit that the exact origin of the conductance degradation is not trivial and more in depth work is needed. But, in our case, the series resistance interpretation was found more physically coherent than the extraction of the effective channel mobility from the split $C-V$ technique that may lead to erroneous values and anomalous trends with $V_{\mathrm{GS}}$.

\section{Conflict of Interests}

The authors have no conflict of interests associated with this paper.

\section{Acknowledgment}

The authors would like to acknowledge the assistance of Albert Ciprut in the TCAD simulation work.

\section{References}

[1] D. Esseni, P. Palestri, and L. Selmi, "Nanoscale MOS transistors, semi-classical transport and applications," Cambridge University Press, 2011.

[2] A. Karsenty, A. Sa'ar, N. Ben-Yosef, and J. Shappir, "Enhanced electroluminescence in silicon-on-insulator metal-oxidesemiconductor transistors with thin silicon layer," Applied Physics Letters, vol. 82, no. 26, pp. 4830-4832, 2003.

[3] D. Abraham, A. Chelly, D. Elbaz, S. Schiff, M. Nabozny, and Z. Zalevsky, "Modeling of current-voltage characteristics of the photoactivated device based on SOI technology," Active and Passive Electronic Components, vol. 2012, Article ID 276145, 7 pages, 2012.

[4] M. Chan, F. Assaderaghi, S. A. Parke, S. S. Yuen, C. Hu, and P. K. Ko, "Recess channel structure for reducing source/drain series resistance in ultra-thin SOI MOSFET," in Proceedings of the IEEE International SOI Conference, pp. 172-173, October 1993. 
[5] S. Cristaloveanu and S. S. Li, Methods of Forming SOI WafersElectrical Characterization of S.O.I. Material and Devices, Ch 2, Kluwer Academic Publishers, 1995.

[6] S. Cristoloveanu, "Status, trends and challenges of siliconon-insulator technology-SOI metamorphosis silicon," IEEE Circuits and Devices Magazine, vol. 15, no. 1, pp. 26-32, 1999.

[7] M. Bruel, B. Aspar, B. Charlet et al., "“'Smart cut”: a promising new SOI material technology," in Proceedings of the IEEE International SOI Conference, pp. 178-179, October 1995.

[8] B. Dance, "European SOI Comes of Age," Semiconductor International, pp. 83-90, 1994.

[9] L. Peters, "SOI takes over where silicon leaves off," Semiconductor International, 1993.

[10] M. Alles and S. Wilson, "Thin film silicon on insulator: an enabling technology," Semiconductor International, vol. 20, no. 4, pp. 67-74, 1997.

[11] A. Auberton-Herve and T. Nishimura, "SOI-based devices. Status overview," Solid State Technology, vol. 37, no. 7, 1994.

[12] A. J. Auberton-Herve, J. M. Lamure, T. Barge, M. Bruel, B. Aspar, and J. L. Pelloie, "SOI Materials for ULSI Applications," Semiconductor International, pp. 97-104, 1995.

[13] T. E. Thompson, "SOI sandwich promises fast, low-power ICs," Electronic Business Today, pp. 43-47, 1995.

[14] J. Rhea, "DARPA low power program aims at mobile applications," Military \& Aerospace Electronics, 1996.

[15] P. H. Singer, "U. S. Chipmakers: Penny-Wise, Million-Dollar Foolish," Semiconductor International, 1995.

[16] M. Bruel, B. Aspar, B. Charlet et al., “"Smart cut”: a promising new SOI material technology," in Proceedings of the IEEE International SOI Conference, pp. 178-179, October 1995.

[17] A. Karsenty, Study of the electrical and electro-optical phenomena in thin SOI MOS transistors [Ph.D. thesis], Hebrew University of Jerusalem, The Fredy \& Nadine Hermann Graduate School of Applied Science, Microelectronics \& Electro-Optics Divisions, 2003.

[18] L. Do Thanh and P. Balk, "Elimination and generation of $\mathrm{Si}-\mathrm{SiO}_{2}$ interface traps by low temperature hydrogen annealing," Journal of The Electrochemical Society, vol. 135, no. 7, pp. 1797-1801, 1988.

[19] S. Cristoloveanu and T. Ouisse, in The Physics and Chemistry of $\mathrm{SiO}_{2}$ and the $\mathrm{Si}_{-} \mathrm{SiO}_{2}$ Interface 2, C. R. Helms and B. E. Deal, Eds., pp. 309-318, Plenum Press, New York, NY, USA, 1993.

[20] V. V. Afanos'ev, A. G. Revesz, and H. L. Hughes, "Confinement phenomena in buried oxides of SIMOX structures as affected by processing," Journal of the Electrochemical Society, vol. 143, no. 2, pp. 695-700, 1996.

[21] J. Wan, C. Le Royer, A. Zaslavsky, and S. Cristoloveanu, "Gateinduced drain leakage in FD-SOI devices: what the TFET teaches us about the MOSFET,' Microelectronic Engineering, vol. 88, no. 7, pp. 1301-1304, 2011.

[22] K. Uchida, H. Watanabe, A. Kinoshita, J. Koga, T. Numata, and S. Takagi, "Experimental study on carrier transport mechanism in ultrathin-body SOI n- and p-MOSFETs with SOI thickness less than $5 \mathrm{~nm}$," in Proceedings of the IEEE International Devices Meeting (IEDM '02), pp. 47-50, December 2002.

[23] K. Uchida, J. Koga, and S. Takagi, "Experimental study on carrier transport mechanisms in double- and single-gate ultrathinbody MOSFETs-Coulomb scattering, volume inversion, and $\delta$ TSOI-induced scattering," in Proceedings of the IEEE International Electron Devices Meeting, pp. 805-808, December 2003.

[24] K. Uchida and S. Takagi, "Carrier scattering induced by thickness fluctuation of silicon-on-insulator film in ultrathin-body metal-oxide-semiconductor field-effect transistors," Applied Physics Letters, vol. 82, no. 17, pp. 2916-2918, 2003.

[25] D. Esseni, A. Abramo, L. Selmi, and E. Sangiorgi, "Physically based modeling of low field electron mobility in ultra-thin single and double-Gate SOI n-MOSFETs," IEEE Transactions on Electron Devices, vol. 50, no. 12, pp. 2445-2455, 2003.

[26] F. Gámiz, J. B. Roldán, P. Cartujo-Cassinello, J. A. LópezVillanueva, and P. Cartujo, "Role of surface-roughness scattering in double gate silicon-on-insulator inversion layers," Journal of Applied Physics, vol. 89, no. 3, pp. 1764-1770, 2001.

[27] F. Gamiz, J. B. Roldán, and J. A. López-Villanueva, "Phononlimited electron mobility in ultrathin silicon-on-insulator inversion layers," Journal of Applied Physics, vol. 83, pp. 48024806, 1998.

[28] K. Lee, M. Shur, T. A. Fjeldly, and T. Ytterdal, Semiconductor Device Modeling For VLSI, Prentice Hall Series in Electronics and VLSI, C. S. Sodini Series, 1993.

[29] K. K. Ng and W. T. Lynch, "Analysis of the gate-voltagedependent series resistance of MOSFET's ", IEEE Transactions on Electron Devices, vol. 33, no. 7, pp. 965-972, 1986.

[30] M. Y. Kwong, C. Choi, R. Kasnavi, P. Griffin, and R. W. Dutton, "Series resistance calculation for source/drain extension regions using 2-D device simulation," IEEE Transactions on Electron Devices, vol. 49, no. 7, pp. 1219-1226, 2002.

[31] J. G. J. Chern, P. Chang, R. F. Motta, and N. Godinho, "A new method to determine MOSFET Channel Length," IEEE Electron Device Letters, vol. 1, no. 9, pp. 170-173, 1980.

[32] C. H. Chu Hao, B. Cabon-Till, S. Cristoloveanu, and G. Ghibaudo, "Experimental determination of short-channel MOSFET parameters," Solid State Electronics, vol. 28, no. 10, pp. 1025-1030, 1985.

[33] K. Romanjek, F. Andrieu, T. Ernst, and G. Ghibaudo, "Improved split C-V method for effective mobility extraction in sub- $0.1-\mu \mathrm{m}$ Si MOSFETs," IEEE Electron Device Letters, vol. 25, no. 8, pp. 583-585, 2004.

[34] D. K. Schroder, Semiconductor Material and Device Characterization, Ch 8, Wiley, 2nd edition, 1998.

[35] F. A. Ikraiam, R. B. Beck, and A. Jakubowski, "Modeling of SOIMOS capacitors C-V behavior: partially- and fully-depleted cases," IEEE Transactions on Electron Devices, vol. 45, no. 5, pp. 1026-1032, 1998.

[36] A. I. Khan, M. K. Ashraf, and A. Haque, "Influence of wave function penetration on short channel effects in nanoscale double gate MOSFETs", in Proceedings of the IEEE Conference on Electron Devices and Solid-State Circuits (EDSSC '07), pp. 109112, December 2007. 

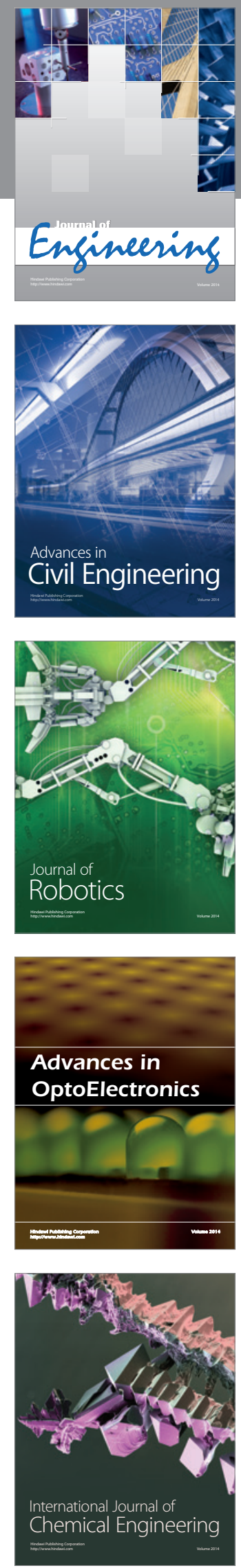

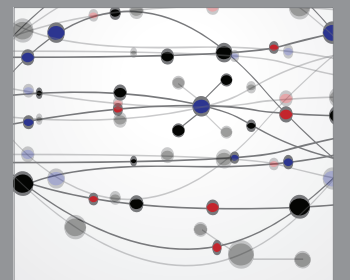

The Scientific World Journal
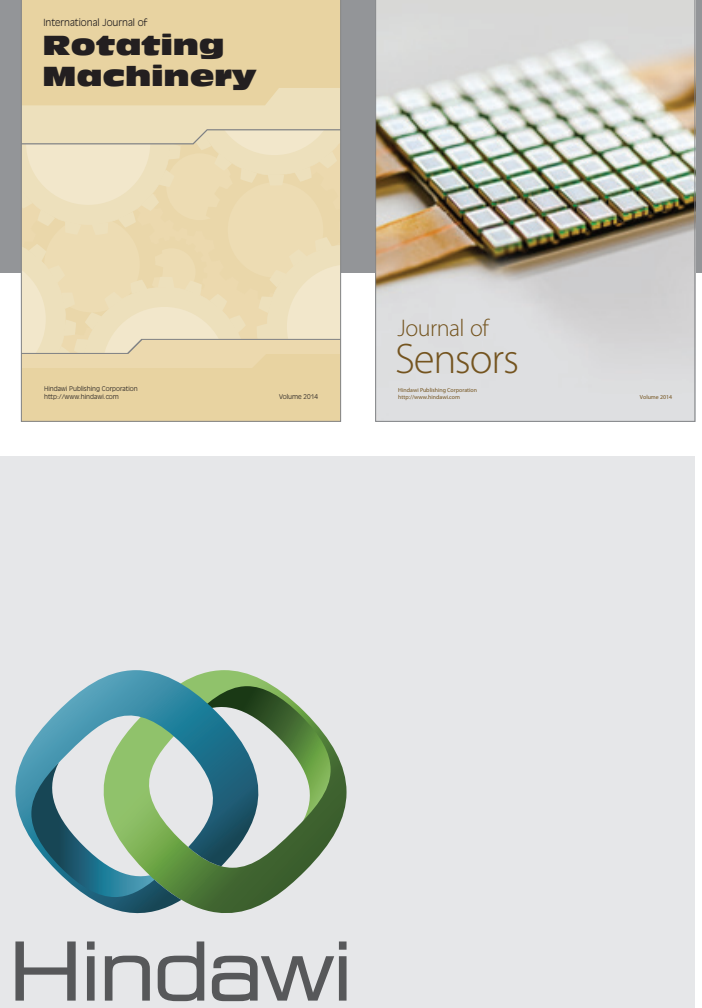

Submit your manuscripts at http://www.hindawi.com
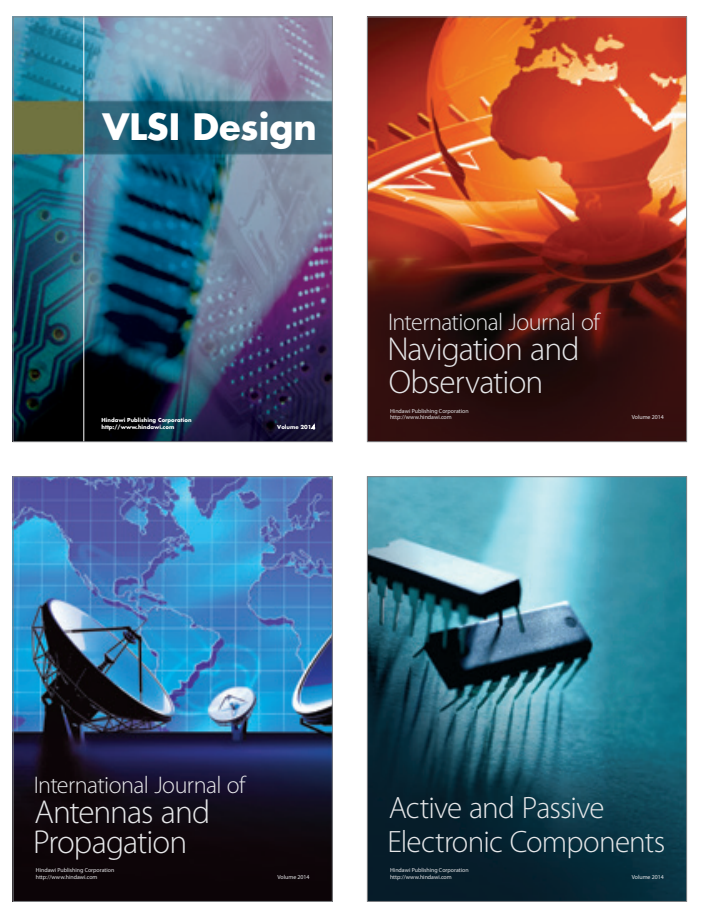
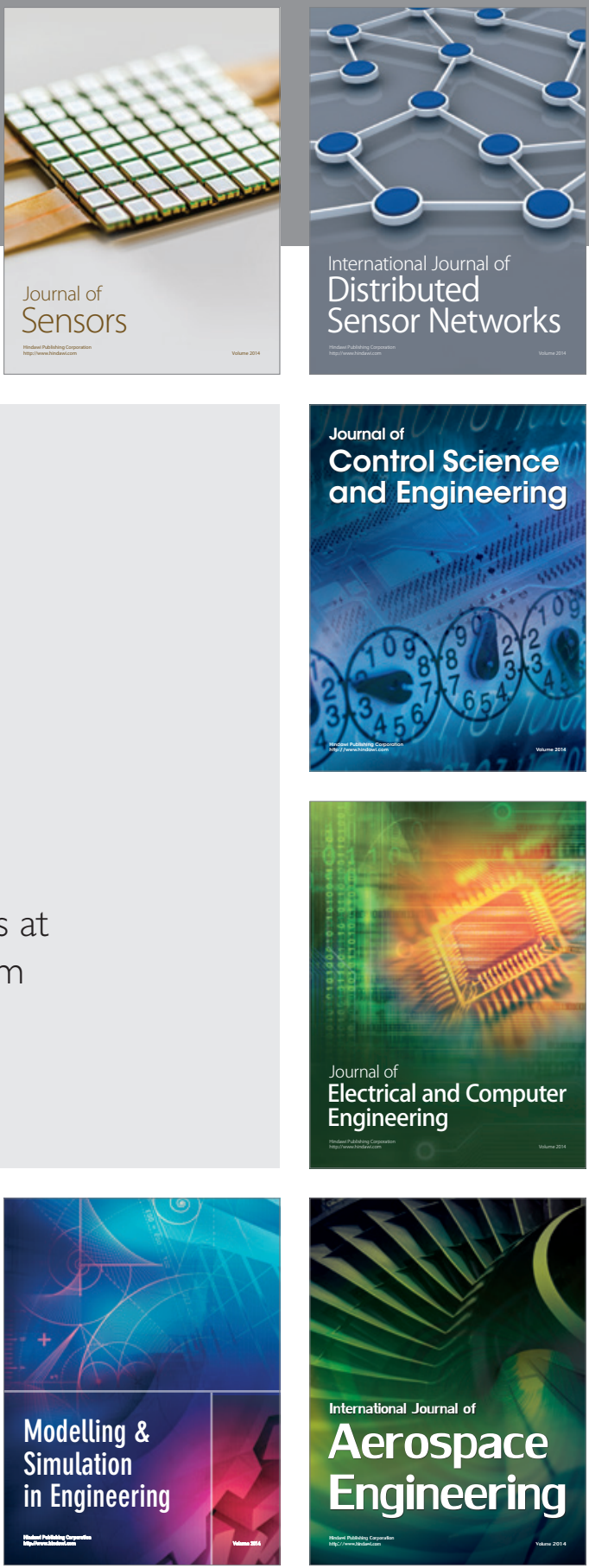

Journal of

Control Science

and Engineering
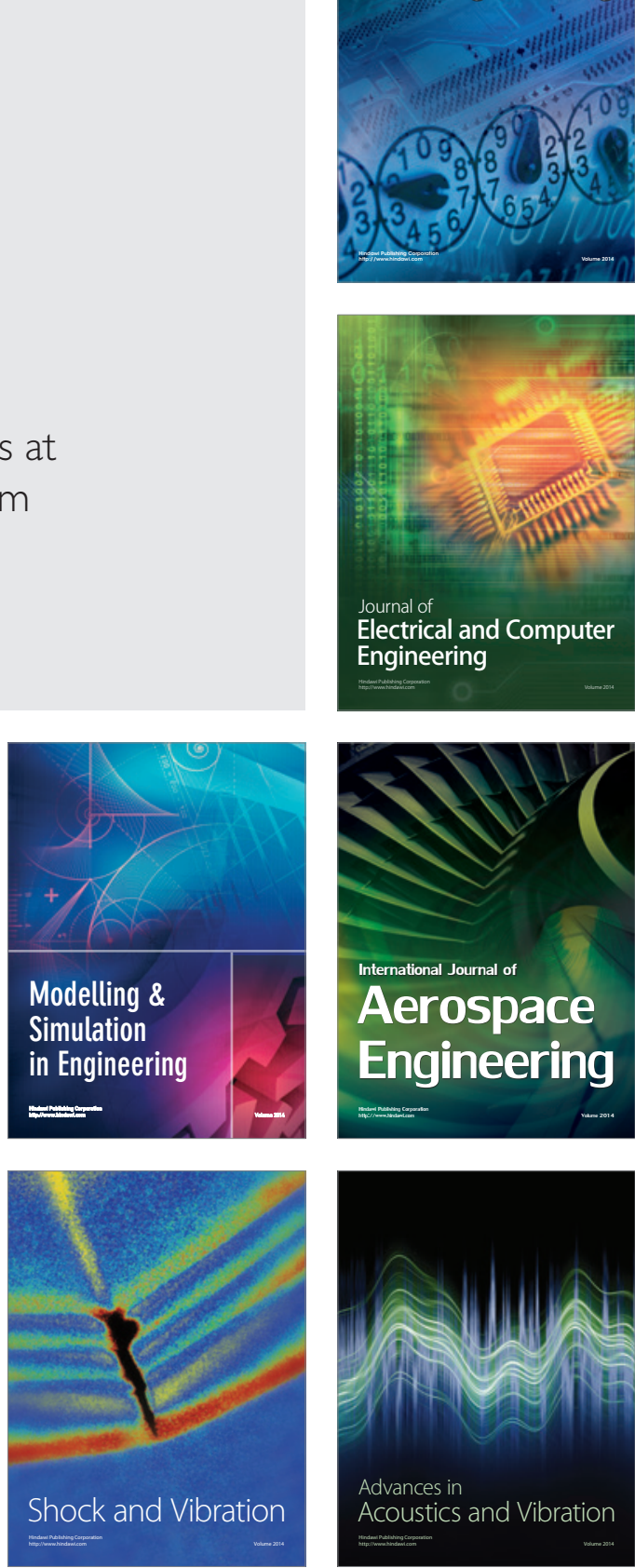